\title{
Screening of Clostridium difficile Isolates for Metallo-Resistant Gene and Extended Spectrum Beta-Lactamases
}

\author{
Nafisat A. Kachalla*, Ja'afaru M. Inuwa, Halima Isa, Jude F. Chanji \\ Department of Microbiology, School of Life Sciences, Modibbo Adama University Yola, Nigeria
}

Received March 10, 2021; Revised June 30, 2021; Accepted July 19, 2021

\section{Cite This Paper in the following Citation Styles}

(a): [1] Nafisat A. Kachalla, Ja'afaru M. Inuwa, Halima Isa, Jude F. Chanji, "Screening of Clostridium difficile Isolates for Metallo-Resistant Gene and Extended Spectrum Beta-Lactamases," Universal Journal of Microbiology Research, Vol. 9, No. 1, pp. 1 - 7, 2021. DOI: 10.13189/ujmr.2021.090101.

(b): Nafisat A. Kachalla, Ja'afaru M. Inuwa, Halima Isa, Jude F. Chanji (2021). Screening of Clostridium difficile Isolates for Metallo-Resistant Gene and Extended Spectrum Beta-Lactamases. Universal Journal of Microbiology Research, 9(1), 1 - 7. DOI: 10.13189/ujmr.2021.090101.

Copyright $@ 2021$ by authors, all rights reserved. Authors agree that this article remains permanently open access under the terms of the Creative Commons Attribution License 4.0 International License

\begin{abstract}
Clostridium difficile naturally inhabits intestinal tract of animals including humans. Spores of $C$. difficile are known contaminant in the Environment. Indiscriminate use of antibiotics has led to the emergence of a powerful resistance determinant (known as Metallo resistant genes) in many bacteria worldwide. Multidrug resistant bacteria (MRB) pose threats to health globally. This study aims to determine the distribution of Metallo resistant Clostridium difficile in hospital environment within Yola. A total of 150 surface samples from the hospital wards were collected from Federal Medical Centre,
\end{abstract} Yola (FMC) and Specialist hospital, Yola (SHY) Adamawa state, Nigeria. Clostridium difficile were recovered by inoculating samples in modified Cycloserine-cefoxitin fructose broth (CCFB) and Cycloserine-cefoxitin fructose agar (CCFA). Screening of isolates for extended spectrum $\beta$-lactamase (ESBL) and metallo- $\beta$-lactamase enzymes was done by double disc diffusion method and Imipenem-EDTA combined disc test respectively. A total of $18 \mathrm{C}$. difficile isolates were obtained and found to be extended spectrum $\beta$-lactamase (ESBL) positive. $16(88.89 \%)$ of the Clostridium difficile were found to be metallo- $\beta$-lactamase positive. Polymerase chain reaction showed that $11(61.1 \%)$ of the isolates possess bla-IMP metallo resistant gene. This study suggests that multidrug resistant $C$. difficile with metallo resistant genes are wide spread in hospital settings and there is need for relevant authorities to improve on the sanitization of environment as well as continuous surveillance to hinder $C$. difficile transmission.

Keywords C. difficile, Hospital Wards, Metallo Resistant Gene, Extended Beta Lactamase

\section{Introduction}

Clostridium difficile infection has been regarded as a nosocomial infection in human especially in patient receiving prolonged antibiotic therapy [1]. Infection with Clostridium difficile causes various outcome, ranging from asymptomatic colonization to pseudomembranous colitis (PMC), which may result in death if untreated [2]. The most important determinants of Clostridium difficile infection are exposed to the organism and treatment with antibiotic [3]. The use of antibiotics leads to killing of antibiotic-sensitive organisms and colonization by $C$. difficile leading to clinical conditions [4]. The role of the environment as a potential reservoir for MBL C. difficile and its significance in infection remains unclear in most African countries.

Bacteria with multidrug resistant gene pose an impending threat to health [5]. The widespread, indiscriminate and increasing use of antibiotic is the notable cause of the emergence of multidrug resistant 
bacteria. ßeta-Lactamases are enzymes which hydrolyze the $\beta$-lactam ring of Penicillins, Cephalosporins, Monobactams and Carbapenems. This is an important mechanism of microbial resistance to $\beta$-lactam antibiotic [6]. Extended spectrum Beta-lactamases are major mechanism of resistance to the second, third and fourth generation Cephalosporins [7]. These enzymes hydrolyze and confer resistance to modern cephalosporin. Infections with metallo- $\beta$-lactamases producing bacteria are difficult to manage because of their zinc-catalyzed mechanism of hydrolysis [8]. Genes encoding for MBL are located on the integron structures that resides on transposons or plasmids [9] thus enhancing dissemination. They are unique in their ability to hydrolyze carbapenems and be inhibited by EDTA chelators of $\mathrm{Zn}^{2+}[10]$. Clostridium difficile have several MBL genes among which are beta-lactamase like protein, beta-lactamase like hydrolase, beta-lactamase inhibitor protein II, metallo-beta lactamase superfamily protein, metallo-beta lactamase superfamily hydrolase, metallo-beta lactamase superfamily exported protein, cell surface protein penicillin-binding protein amongst others [11]. bla-IMP and bla-VIM are the most common MBL genes described throughout the world [12]. bla-AIM, bla-GIM, bla-SPM, bla-SIM, NDM-1 are the other types of MBL genes found only sporadically in some geographical regions [13]. Difficulty in management and increased hospital stay of patients with serious infections due to MBL organism are attributed to continuous treatment with antibiotic to which complete resistance has developed [14]. Therefore, detection of MBL producing organisms especially $C$. difficile is highly significant for optimal treatment and controlling the spread of drug resistance organism.

\section{Methodology}

\subsection{Sample Collection}

One hundred and fifty surface samples were collected, 75 samples each from Federal Medical Centre Yola (FMC) and Specialist Hospital Yola (SHY). Using sterile moistened swab, samples were collected from medical ward, intensive care unit (ICU) and female surgical wards. Patient's bed sheet, bed railings, table tops, toilets and windows were specific sites sampled.

\subsection{Isolation of Clostridium Difficile}

The swab containing the specimen was immersed in Cycloserine-Cefoxitin Fructose broth (CCFB) supplemented with taurocholate to enhance recovery of spore and it was then incubated anaerobically at $35^{\circ} \mathrm{C}$ for 7 days. (CCFB). A loop full of cultured broth was then inoculated onto Cycloserine-Cefoxitin fructose Agar (CCFA) composed of $4 \%$ proteose peptone, $0.01 \%$ $\mathrm{MgSO}_{4}, 0.2 \% \mathrm{NaCl}, 0.5 \% \mathrm{Na}_{2} \mathrm{HPO}_{4}, 0.1 \% \mathrm{KH}_{2} \mathrm{PO}_{4}$,
$0.6 \%$ fructose, $1.5 \%$ agar at $\mathrm{pH} 7.4$ supplemented with $250 \mathrm{mg} / \mathrm{ml}$, D-Cycloserine and $8 \mathrm{mg} / \mathrm{ml}$ cefoxitin [15]. It was then incubated anaerobically at $37^{\circ} \mathrm{C}$ for 48 hours. The isolates obtained were identified by morphological characteristics, odour, biochemical test (catalase, oxidase), motility test and Gram stain. Pure isolates were stored in $\mathrm{CCFB}$ and Brain heart infusion broth (BHI) at $-20^{\circ} \mathrm{C}$ for further studies.

\subsection{Antimicrobial Susceptibility Testing (MIC)}

The inoculum of isolates was prepared from overnight cultures of organisms. A sterilized wire loop was used to emulsify a colony of the test organism in $4 \mathrm{ml}$ of sterile nutrient broth which was then incubated anaerobically for 2 hours at $37{ }^{\circ} \mathrm{C}$. The nutrient's broth turbidity was matched to 0.5 McFarland Standard [16]. The Minimum inhibitory concentration (MIC) was determined following the Clinical and Laboratory Standard Institute [17] using the well diffusion method. The antibiotics used includes Metronidazole $(0.5-32 \mu \mathrm{g} / \mathrm{ml})$, Ciprofloxacin (0.5-32 $\mu \mathrm{g} / \mathrm{ml})$, Erythromycin $(0.5-32 \mu \mathrm{g} / \mathrm{ml})$, Tetracycline (1-64 $\mu \mathrm{g} / \mathrm{ml})$ and Clindamycin $(0.5-32 \mu \mathrm{g} / \mathrm{ml})$. Varying concentrations were prepared by serial dilution from stock solution that was prepared by dissolving each tablet of the antibiotic in $100 \mathrm{ml}$ of distilled water in a sterile container. The test organism was inoculated unto Mueller Hinton agar using a sterile cotton swab to streaked evenly over the surface of the agar [18]. Five wells were made on each of the streaked plates corresponding to the five antibiotics to be used using a sterile cork borer. $20 \mu \mathrm{l}$ of the various antibiotic concentration was dispensed into each of the well and was allowed to diffuse for three hours on the bench. All the inoculated plates were incubated anaerobically at $37^{\circ} \mathrm{C}$ for 48 hours in an anaerobic jar. The MIC was recorded for each isolate after 48 hours [19].

\subsection{Phenotypic Detection of Extended Spectrum $\beta$-Lactamase (ESBL)}

The phenotypic detection of ESBL was performed on Mueller Hinton agar using Kirby-Bauer double disk diffusion method according to technique described by Wayne [20]. Amoxicillin-clavulanic acid and Ceftazidime disc were used. Inoculum was prepared from overnight cultures of the test organism. Using a sterile swab, test organisms were inoculated onto Mueller Hinton agar. A disc containing $30 \mu \mathrm{g}$ of Ceftazidime was placed on the agar at a distance of $20 \mathrm{~mm}$ from the Amoxicillinclavulanic acid $(30 \mu \mathrm{g})$ disc. The plates were incubated anaerobically at $37{ }^{\circ} \mathrm{C}$ for 24 hours in an anaerobic jar. The inhibition zones were observed and recorded.

\subsection{Phenotypic Detection of Metallo $\beta$-Lactamases}

The production of metallo beta lactamase enzyme was 
determined following the method described by Yong et al., [21]. The Imipenem combine disc synergy was done by placing two $(10 \mu \mathrm{g})$ Imipenem disc at a distance of $20 \mathrm{~mm}$ from each other and $10 \mu \mathrm{l}$ of EDTA solution was added to one of them to the desired concentration of $750 \mu \mathrm{g}$ on the Mueller Hinton agar inoculated with test organism. The inhibition zones of the Imipenem and Imipenem-EDTA disc were compared after 18-24 hours of anaerobic incubation at $37^{\circ} \mathrm{C}$. An increased inhibition zone with the Imipenem and EDTA disc $>7 \mathrm{~mm}$ than the Imipenem disc alone was considered as metallo- $\beta$-lactamase positive [22].

\subsection{Molecular detection of bla-IMP gene}

\subsubsection{DNA Extraction}

DNA extraction was performed using ZR Bacterial DNA MiniPrep ${ }^{\mathrm{TM}}$ kit following the manufacturers instruction.

\subsubsection{Polymerase Chain Reaction (PCR)}

Metallo resistant gene sequence of $C$. difficile was obtained from NCBI and primer pairs were designed using primer blast tool of NCBI to amplify a $597 \mathrm{bp}$ fragment of the bla-IMP gene. The primer sequences obtained are forward-(5'AGGTGGCACGAATACAGGAA-3') and reverse-(5'ACTTGCTTGCCATGCCCTAA-3'). The Polymerase chain reaction (PCR) analysis was performed as described by Indra et al., [23]. The PCR reaction was performed in a final volume of $25 \mu \mathrm{l}$ containing the following: $12.5 \mu \mathrm{l}$ HostarTaq PCR master mix (Qiagen, Germany), $5.0 \mu \mathrm{l}$ Q solution (Qiagen, Germany), $2.5 \mu \mathrm{l}$ Coral load (Qiagen, Germany), $2 \mu \mathrm{l}$ each $(0.6 \mu \mathrm{M})$ of forward and reverse primer and $1 \mu 1$ of DNA sample. PCR amplification was performed as follows: one cycle of initial denaturation at $94{ }^{\circ} \mathrm{C}$ for 30 seconds; 35 cycles of denaturation at $94^{\circ} \mathrm{C}$ for 1 minute; Annealing at $48^{\circ} \mathrm{C}$ for 1 minute; Extension at $72{ }^{\circ} \mathrm{C}$ for 30 seconds and final extension at $72{ }^{\circ} \mathrm{C}$ for 10 minutes. Amplicons were analyzed by agarose gel electrophoresis using $1.5 \%$ agarose gel for 60 minutes at 100 volts.

\section{Results}

\subsection{Isolation of Clostridium Difficile}

Eighteen (12\%) positive isolates of $C$. difficile were obtained with a distribution of 8 and 10 from Specialist Hospital Yola and the Federal Medical Centre, Yola respectively. The colonies are approximately $4 \mathrm{~mm}$ in diameter, yellow and ground glass-like with a slightly filamentous edge and distinctive horse urine odor. Gram stain showed that isolates were gram positive bacilli in cluster. Biochemically the isolates were catalase and oxidase negative and were motile.

\subsection{Antimicrobial Susceptibility Testing}

Antibiotic susceptibility tests reveal that Clostridium difficile isolated were resistant to an array of antibiotics. The isolates were found to be resistant to Ciprofloxacin (MIC $>64 \mu \mathrm{g} / \mathrm{ml}$ ), Erythromycin (MIC $>64 \mu \mathrm{g} / \mathrm{ml}$ ), Metronidazole (MIC $64 \mu \mathrm{g} / \mathrm{ml}$ ), Tetracycline (MIC > 128 $\mu \mathrm{g} / \mathrm{ml}$ ) and clindamycin (MIC $>64 \mu \mathrm{g} / \mathrm{ml}$ ).

\subsection{Phenotypic Detection of Extended Spectrum $\beta$-Lactamase (ESBL) and Metallo Beta Lactamase}

ESBL detection showed that all the 18 (Eighteen) isolates were ESBL positive. After anaerobic incubation at $37^{\circ} \mathrm{C}$ for 48 hours, the inhibition zone around Amoxicillin-clavulanic acid discs showed a $5 \mathrm{~mm}$ differentiation $(21 \mathrm{~mm})$ as against the zone of inhibition around the Ceftazidime disc $(16 \mathrm{~mm})$ alone (Plate I). Similarly, the phenotypic detection of metallo- $\beta$-lactamase by Imipenem-EDTA combined disc test, showed that $16(88.89 \%)$ out of the 18 isolates were positive. The inhibition zone around Imipenem-EDTA disc was $>7 \mathrm{~mm}(23 \mathrm{~mm})$ than the inhibition zone around the Imipenem disc (16 mm) alone (Plate II). Eleven (11) out of the 18 isolates were positive for bla-IMP gene (Plate III).

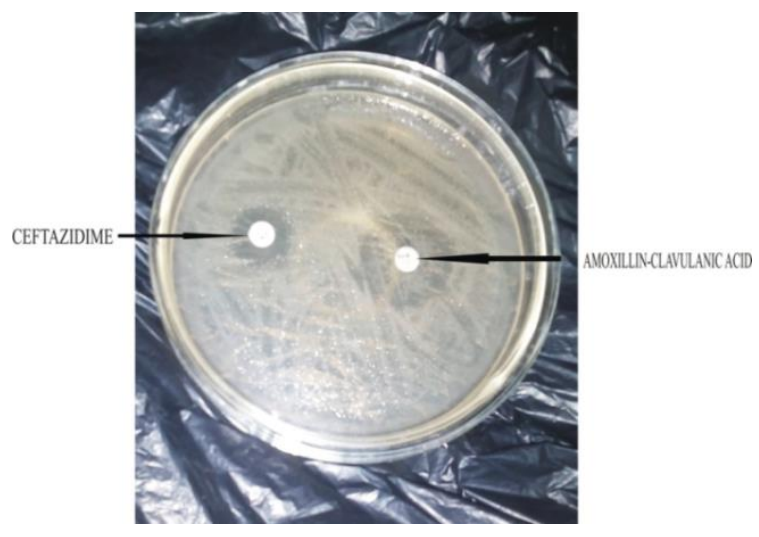

Plate I. ESBL positive showing Amoxicillin- Clavulanic acid disc (right) with increased zone of inhibition than ceftazidime disc (left) 


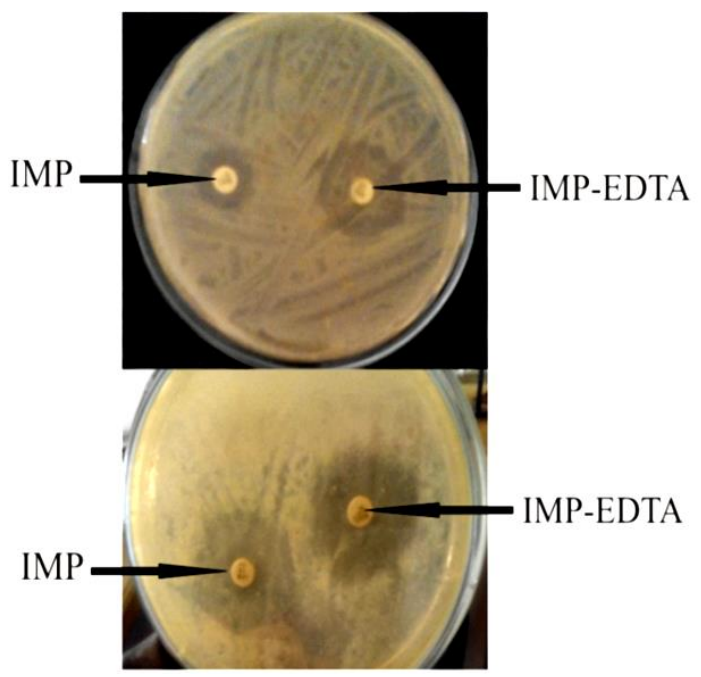

Plate II. Metallo $\beta$ - lactamase positive, IMP-EDTA increased clear zone of inhibition on the right (upper). Metallo $\beta$-lactamase negative (Both IMP-EDTA and IMP disc have increased zones of inhibitions (lower)

ATCATGCTCAGATGAACGCTGGCGGCGTGCCTAACACATGCAAGTTGAGCGATTTACTTCGGTAAAGAGC GGCGGACGGGTGAGTAACGCGTGGGTAACCTACCCTGTACACACGGATAACATACCGAAAGGTATGCTA ATACGGGATAATATATTTGAGAGGCATCTCTTGAATATCAAAGGTGAGCCAGTACAGGATGGACCCGCGT CTGATTAGCTAGTTGGTAAGGTAACGGCTTACCAAGGCGACGATCAGTAGCCGACCTGAGAGGGTGATCG GCCACATTGGAACTGAGACACGGTCCAAACTCTACGGGAGGCAGCAGTGGGGAATATTGCACAATGGGC GAAAGCCTGATGCAGCAACGCCGCGTGAGTGATGAAGGCCTTCGGGTCGTAAAACTCTGTCCTCAAGGAA GATAATGACGGTACTTGAGGAGGAAGCCCCGGCTAACTACGTGCCANCAGCCCGGTAATACGTAGGGGG CTAGCGTTATCCGGATTTACTGGGCGTAAAGGGTGCGTAGGCGGTCTTTCAAGTCAGGAGTGAAAGGCTA CGGCTCAACCGTAGTAAGCTCTTGAAACTGGGAGACTTGAGTGCAGGAGAGGAGAGTGGAATTCCTAGT GTAGCGGTGAAATGCGTAGATATTAGGAGGAACACCAGTTGCGAAGGCGGCTCTCTGGACTGTAACTGAC GCTGAGGCACGAAAGCGTGGGGAGCAAACAGGATTAGATACCCTGGTAGTCCACGCTGTAAACGATGAG TACTAGGTGTCGGGGGTTACCCCTTCGGTGCCGCACTAACGCATTAAGTACTCCGCCTGGGAAGTACGCT CGCAAGAGTGAAACTCAAAGGAATTGACGGGGACCCGCACAAGTAGCGGAGCATGTGGTTTAATTCGAA GCAACGCGAAGAACCTTACCTAAGCTTGACATCCCAATGACATCTCCTTAATCGGAGAGTTCCCTTCGGG GACATTGGTGACAGGTGGTGCATGGTTGTCGTCAGCTCGTGTCGTGAGATGTTGGGTTAAGTCCCGCAAC GAGCGCAACCCTTGTCTTTAGTTGCCATCATTAAGTTGGGCACTCTGAGAGACTGCCAGGGATAACCTGG AGGAAGGTGGGGATGACGTCAAATCATCATGCCCCTTATGCTTAGGGCTACACACGTGCTACAATGGGTA GTACAGAGGGTTGCCAAGCCGTAAGGTGGAGCTAATCCCTTAAAGCTACTCTCAGTTCGGATTGTAGGCT GAAACTCGCCTACATGAAGCTGGAGTTATATAATCGCAATCAAAATGCTGCGGTGAATGCGTTCCCGGGG TCTTTACACACCGCCCGTCACACCCGGGAGTTGGAAACGCCCGAAGCCGAATTATCTAACCTTTTGGAAN AATCTCGAAAGTGGAATCAATAACTTGGGTAATCGTAACAAGGTAACCGTATCGGAAGGT

Figure 1. 16S RNA sequence of Clostridium difficile

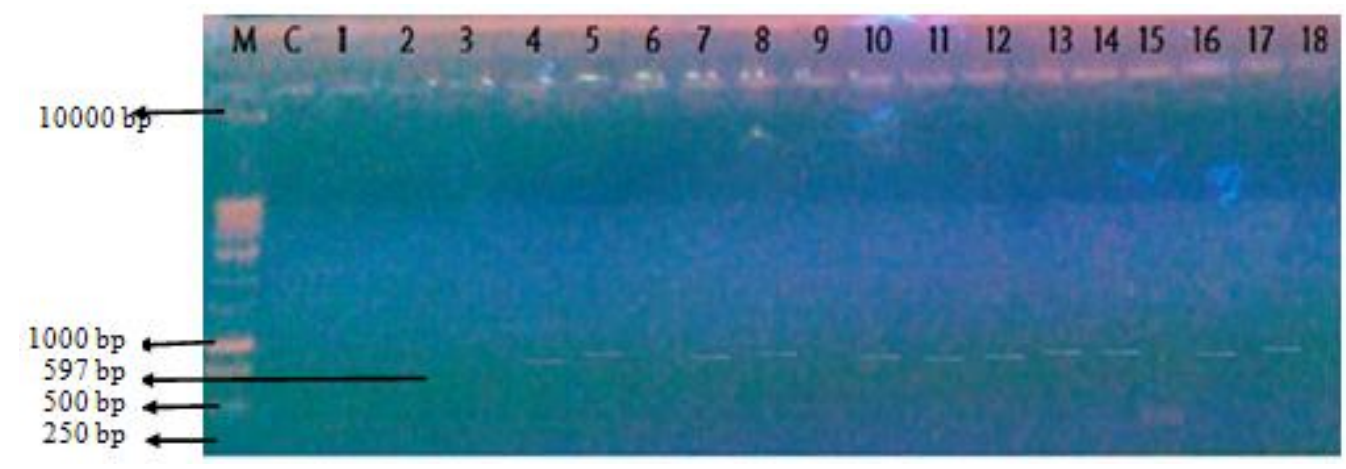

Plate III. $1 \%$ agarose gel showing 597 bp Bla protein-like amplicons Lane M: DNA ladder (1Kb), Lanes 4,5,7,8,10,11,12,13,14,16 and 17 is positive for Bla protein-like metallo resistant gene. Lanes 1,2,3,6,9,15 and 18 are negative for Bla protein-like metallo resistant gene 


\section{Discussion}

The results in this research were not unexpected as $C$. difficile has been reported to be a nosocomial pathogen. $C$. difficile infected patient are reservoirs as well as disseminators as can excretes are more than $10^{5} \mathrm{C}$. difficile per gram of feces. $C$. difficile spores are highly resistant and can survive in the environment for months [24]. This explains why the toilets $(38.9 \%)$ are the most contaminated sites as observed in this study. Research has shown that $C$. difficile spores are found in $34-58 \%$ of sites in hospital environment [25], including after disinfection [26] and commodes, bed frames, toilets floors are the most contaminated sites. A study by Fawley and Wilcox [25] showed that $C$. difficile remained viable in one third of surface samples taken from the hospital rooms of pseudomembranous colitis patients with (PMC). Spores on equipment's and hands of health workers facilitates spread of $C$. difficile and hence are potential vehicle in cross contamination.

Studies conducted by Adebgoyega, [27], Titov, et al., [28] and Fawley and Wilcox [25] had similar findings. The hospital, particularly the ICU harbors strains of $C$. difficile which may have been introduced by hospitalized patients or staff and easily transmitted to other patients as well as the environment. Adebgoyega, [27] also reported $11.7 \%$ recovery rate of $C$. difficile in medical wards. Another study with $12.5 \%$ rate from the Lagos University Teaching Hospital (LUTH) environment depicts that the source of transmission of this organism may be hospitalized patients. The problems faced with ESBL screening and identification as ESBL pathogens by laboratories in underdeveloped countries have brought about variations in the in vitro pattern of resistant to $\beta$-lactam agents. World Health Organization (WHO) and the Centre for Disease Control (CDC) have raised concerns about the inability of many laboratories to detect ESBL-producing microorganism [29]. C. difficile is a multidrug resistant bacterium [30] and research has shown that $C$. difficile carries a $c f r$ protein like gene that confers multiple antibiotic resistance by the same mechanism as cfr gene in Enterobacteriacae. Two separate studies carried out by Stiefel and Nerandzic in 2014, also revealed that Clostridium difficile are Extended Spectrum Beta-lactamases (ESBL) producers [31]. Standardized method for screening metallo beta-lactamase (MBL) in clinical isolates has not been recommended. However, different studies have reported the use of methods like Imipenem-EDTA combined disc test, double-disc synergy test using Imipenem and EDTA, E-test and modified Hodges test [22]. This study showed the reliability of combined disc diffusion test method (CDDT). Previous studies have shown that more organism was found to be positive for MBL by Imipenem-EDTA disc than Ceftazidime disc. MBL producing organism might have alternative mechanism of resistance and Behera et al., [22] suggest that using Ceftazidime instead of Imipenem disc will not show MBL production. Yan et al., [32] also affirms that the Imipenem-EDTA combined disc test was the most sensitive for phenotypic detection of metallo beta-lactamase production.

In contrast to phenotypic screening of isolates that depicts sixteen (16) isolates as positive for MBL production, the molecular screening indicates that the bla-IMP gene was not the only metallo resistant gene that are harbored by Clostridium difficile but seem to be the dominant, even though the primer used was meant to specifically amplify the bla IMP gene segment and lack of amplifying the whole genome precludes other genes. Nonetheless, the result of this study confirms the presence of metallo resistant gene in Clostridium difficile as previously reported by Manot et al., [11].

\section{Conclusions}

The study confirmed the occurrence of $C$. difficile in the hospitals studied. The $C$. difficile are ESBL producers with approximately $69 \%$ harboring the bla-IMP metallo-resistant gene. All isolates obtained demonstrated a significant level of resistance to the five antibiotics tested. The result depicts that multidrug resistant $C$. difficile is an emerging concern within the hospitals sampled in Adamawa State, Nigeria. This finding poses a threat to the cost associated with Clostridium difficile treatment and may increase a patient's hospital stay. Further studies on potential contamination of surfaces by C. difficile needs to be conducted. Similarly, current disinfection techniques need to be re-evaluated regarding the survival of spore.

\section{Acknowledgements}

The authors wish to thank Dr. Ja'afar N. Ja'afar for assisting in the molecular analysis. Authors contributed equally to the conceptualization of the study.

\section{REFERENCES}

[1] Leffler, D.A., Lamont, J.T." Clostridium difficile infection”. North England Journal of Medicine. Vol. 372 p-1539-1540, 2015 DOI:10.1056/NEJMra 1403772

[2] Kristina R., Torbjörn N., Olov A., Barbro M., Michael T., Åsa J., Thomas Å.” National Surveillance for Clostridioides difficile Infection, Sweden, 2009-2016" Emerging Infectious Diseases Vol. 24, No. 9 p-1617-1625 2018 DOI.org/10.3201/eid2409.171658

[3] Lessa, F.C., Gould, C.V, McDonald, L.C." Current status of C. Difficile Infectious Epidemiology." Clinical Infectious Disease. Vol. 55 suppl 2 p- 65-70, 2012 


\section{DOI:10.1093/cid/cis319}

[4] Fahmi Y. K., Abdul-Naser E. "Clostridium difficile infection: a review of the literature" Asian Pacific Journal of Tropical Medicine Vol. 7(Suppl 1): S6-S13 2014 DOI: 10.1016/S1995-7645(14)60197-8

[5] Shen, J, Wang, Y. Schwarz, S. "Presence and dissemination of multiresistance gene $c f r$ in gram-positive and gramnegative bacteria". Journal of Antimicrobial Agent Chemotherapy Vol. 68 no.8 p-1697-1706, 2013 DOI: 10.1093/jac/dkt092.

[6] Noyal, M.J.C., Menezes, G.A., Harish, B.N., Sujatha, S., Parija, S.C. "Simple screening tests for detection of carbapenamases in clinical isolates of non-fermentative Gram negative bacteria”. Indian Journal of Medical Research. Vol. 129 no. 6 p-707 - 712, 2009.PMID:19692754.

[7] Dubberke E.R., Carling P., Carrico R. "Strategies to prevent Clostridium difficile infections in acute care hospitals: 2014 update". Infections Control and Hospital Epidemiology Vol. 35 p628-645 2014 PubMed: 24799639

[8] Kumarasamy, K.K., Toleman, M. A, Wash, T.R. Bagaria J, Butt F, Balakrishnan R, Chaudary U, Doumith M, Giske C,G, Irfan S, Krishnan P, Kumara V , Maharjan S, Mushtaq S, Noorie T, Paterson D. L, Pearson A, Perry C, Pike, R, Rao B, Ray U, Sarma J.B, Sharma M, Shendan, E, Thirunarayan, M.A, Turton, J, Woodford N."Emergence of a new antibiotic resistance mechanism in India, Pakistan and the UK: a molecular, biological, and epidemiological study". Lancet Infectious Disease. Vol.101 no.9 p-597-608, 2010 DOI:10.1016/S1473-3099(10)70143-2

[9] Massimo S, Stefano D. B., Lynne V. M., Sahil K., Luis F., Nadir A., Fikri M. A., Luca A., Goran A., Miklosh B., Offir B., Walter L. B., Stephen M. B., Adrián C., Miguel A. C., Shirley C., Jill R. C., Jesse C., Federico C., Maria E. C., Raul C., Francesco C., Yunfeng C., Jacek C., Zaza D., Isidoro Di C., Salomone Di S., Irina M. D., Christian E., Edward H. E., Joseph D. F., Gustavo P. F., Jean L. F., Donald E. F., Rita G., Wagih G., Carlos A. G., Ewen A. G., Xavier G., Mohamed H. A., Torsten H., Jae I. K., Tariq I., Arda I., Kamal M. F. I., Francesco M. L., Yeong Y. L., Paul J., Aleksandar K., Peter K. K., Yoram K., Ari L., Varut L., Gustavo M. M, Sanjay M., John E. M., Gokhan M., Ernest E. M., Frederick A. M., Carlos A. O., Leonardo P., Nicola P., Francisco P., Kemal R., Miran R., Boris E. S., Helmut S., Gabriele S., Vishal G. S., Patrizia S., Pierre T., Cristian T., Libor U., Jan U., Pierluigi V., Gian L. B., Fausto C. "2019 update of the WSES guidelines for management of Clostridioides (Clostridium) difficile infection in surgical patients" World Journal of Emergency Surgery Vol.14:8 p1-29 2019 DOI.org/10.1186/s13017-019-0228-3

[10] Queenan, A.M., Bush, K. "Carbapenemases: the versatile beta lactamases". Clinical Microbiology Review. Vol. 20 p-440 - 458, 2007 DOI: 10.1128/CMR00001-07

[11] Manot, M., Caroline, B., Marie, T., David, V., Ivan, M., Claudine, M., Isabelle, M., Bruno, D. "Reannotation of the genome sequence of $C$. difficile strain 630". Journal of Medical Microbiology. Vol. 60 pt.8 p-1193-1199, 2011 DOI:10.1099/jmm.0.030452-0

[12] Amudhan, S.M., Sekar, U., Arunagiri, K., Sekar, B. “OXA beta - lactamase mediated carbapenem resistance in
Acinetobacter baumannii”. Indian Journal of Medical Microbiology. Vol. 29 no.3 p-269 - 274, 2011 DOI:10.4103/0255-0857.857.83911

[13] Cormaglia, G., Giamarellou, H., Rossolini, G.M. "Metallo- $\beta$-Lactamases: a last frontier for $\beta$-Lactams? Lancet Infectious Disease” Vol..11 no.5 p-381-393, 2011 DOI:10.1016/S1473-3099(11)70056-1

[14] Marra, A.R., Pereira, C.A., Gales, A.C., Menezes, L.C., Cal, R.G., Desouza, J.M., Edmond, M. B., Faro C., Wey, S.B."Blood Stream infections with metallo-Beta-lactamase producing Pseudomonas aeruginosa: Epidemiology, Microbiology and Clinical outcomes". Antimicrobial Agents Chemotherapy. Vol. 50 no. 1 p- 388 - 390, 2006 DOI: 10.1128/aac.50.1.388-390

[15] Juanxiu Qin, Yingxin Dai, Xiaowei Ma, Yanan Wang, Qianqian Gao, Huiying Lu, Tianming Li, Hongwei Meng, Qian Liu \& Min "Nosocomial transmission of Clostridium difficile Genotype ST81 in a General Teaching Hospital in China traced by whole genome sequencing Scientific Reports $\mid$ 7: 96272017 DOI:10.1038/s41598-017-09878-8

[16] Brook I, Hannatu M., Wexlex E.J. "Antianaerobic Antimicrobials: Spectrum and Susceptibility Testing". Clinical Microbiology Review Vol. 26 no. 3 p-526-54, 2013 DOI:1: 1128/CMR.00086-12.

[17] Clinical and Laboratory Standards Institute. "Methods for Antimicrobial Susceptibility Testing of Anaerobic Bacteria; Approved Standard," $6^{\text {th }}$ edition. NCCL document M11-A6. Wayne, PA: NCCLS 2004.

[18] Cheesebrough, M. "District Laboratory Practice in Tropical Countries". Part $2^{\text {nd }}$ edition Cambridge University Press.2006 Pp.138.

[19] Martin, H., Willey, B., Low, D.E., Staempfli, H.R., McGeer, A., Boerlin, P., Mulvey, M., Weese, J.S. "Characterization of Clostridium difficile strains isolated from patients in Ontario, Canada, from 2004 to 2006". Journal of Clinical Microbiology. Vol.46 no.9 p-2999-3004,2008 DOI:10.1128/jcm.02437-07

[20] Wayne, P.A." Clinical and laboratory standards institute. Performance standard for antimicrobial susceptibility. $15^{\text {th }}$ edition. Informational supplement: The institute. CLSI/NCCLSM $100-515.2005$

[21] Yong, D., Lee, K., Yum, J.H., Shin, H.B., Rossolini, G.M., Cong, Y. "Imipenem - EDTA disc method for differentiation of metallo-beta-lactamase producing clinical samples of pseudomonas spp. and Acinetobacter spp". Journal of Clinical Microbiology Vol. 40 no. 10 p-3798-3801, 2002. DOI:10.1128/jcm40.10.3798-3801

[22] Behera, B., Das, A., Mathur, P.,Kapil, A. "High prevalence of carbapenem resistant Pseudomonas aeruginosa at a tertiary care centre in north India. Are we under reporting?" Indian Journal of Medical Research.128:324 - 325 Gale Document Number: GALE|A190379233

[23] Indra, A., Schmid, D., Huhulescus, H., Hell, M., Gattninger, R., Hasenbergen, P., Fiedler, A., Wewalkar, G., Allerberger, F."Characterization of clinical Clostridium difficile isolates by PCR ribotyping and detection of toxin genes in Austria, 2006-2007'. Journal of Medical Microbiology. Vol.57pt. 6 p:-702-708, 2008 DOI:10.1099/jmm0.47476-0. 
[24] Yokoe D. S, Anderson D. J, Berenholtz S. M,.”Society for Healthcare Epidemiology of America (SHEA). A compendium of strategies to prevent healthcare-associated infections in acute care hospitals: 2014 updates." Infection Control and Hospital Epidemiology. Vol.35 p967-977, 2014 PubMed: 25026611

[25] Fawley, W.N., Wilcox, M.H. "Molecular typing of endemic Clostridium difficile infection". Epidemiology Infection. Vol. 12 no.3 p-343-350, 2001 DOI:10.1017/S0950268801 006587X

[26] Verity, P., Wilcox, M.H., Fawley, W., Parnell, P. "Prospective evaluation of environmental contamination by Clostridium difficile in isolation side rooms". Journal of Hospital Infection. Vol. 49 no. 3 p-204-209, 2001 DOI:10.1053/jhin.2001.1078

[27] Adegboyega, T.T. Environmental sources Clostridium difficile in Lagos State, Nigeria. Journal of Health, Medicine and Nursing,Vol. 3 p-1-5, 2014 Corpus ID. 28429118

[28] Titov, T., Lebedkova, N., Shabanor, A., Tang, V.S., Cohean, S.H., Silva, J.Jr.,Tang Y. J. "Isolation and molecular characterization of Clostridium difficile strains from patients and the hospital environment in Belarus". Journal of Clinical Microbiology. vol. 38 no.3 p-1200-1202, 2000 PMID:10699022
[29] Hageman, J.C., Fridkin, S.K., Mohammed, J.M., Steward, C.D., Gaynes, R.P., Tenover, F.C.” Antimicrobial proficiency testing of National Nosocomial Infections Surveillance System Hospital Laboratories". Infection Control Hospital Epidemiology Journal. Vol.24 no.5 p-356-361, 2003 DOI:10.1086/502214.

[30] Marin, M., Martin, A., Alcala, L., Cercerado, E., Iglesias, E., Reigados, E., Bouza, E. "Clostridium difficile isolates with high linezolid MICs harbor the multiresistance gene cfr." Antimicrobial Agent Chemotherapy Vol.59 no.1 p-586-589, 2015 DOI:10.1128/AAC.0408214

[31] Stiefel, U., Tima, M.A.,Nerandzic, M.M. Micheal J.,Pult Z., Curtis J. Donskey. "Gastrointestinal colonizati on with a cephalosporinase producing Bacteriodes species preserve colonization resistance against vancomycin-resistant Enterobacteriacae and Clostridium difficile in cephalosporin treated mice". Antimicrobial Agent Chemotherapy vol. 58 no.8 p-4535-4542, 2014 DOI:10.1128/AAC.02782-14

[32] Yan, J.J., Wu, J.J., Tsai, S.H., Chaung, C.L. "Comparison of double disk, combined - disk and E-test methods for detecting metallo-beta-lactamases in gram negative bacilli". Diagnostic Microbiology Infections Disease. Vol. 49 no.1 p- 5-11, 2004 DOI:10.1016/jidigmicrobio2004.01.002 